\title{
MOTIVASI DAN KOMITMEN TERHADAP KINERJA KARYAWAN BAZNAS PROVINSI JAWA TIMUR'
}

\author{
Amalina Rusydina \\ Program Studi S1 Ekonomi Islam - Fakultas Ekonomi dan Bisnis - Universitas Airlangga \\ Email: amalinarus10@gmail.com \\ Ririn Tri Ratnasari \\ Departemen Ekonomi Syariah - Fakultas Ekonomi dan Bisnis - Universitas Airlangga \\ Email: ri.ratnasari@gmail.com
}

\begin{abstract}
:
The research method used in this study is a quantitative approach. The process of collecting data used is a questionnaire. The sample used was the employees of the National Amil Zakat Agency (BAZNAS) of East Java Province with 40 respondents. Sampling using a non-probability sample technique and saturated sample. The analysis technique used in this study is path analysis. The results of this study indicate that each of the three work motivation variables has a significant effect on employees' commitment, employees' commitment has a significant effect on employees' performance, and work motivation has a significant effect on the performance of employees of the Amil Zakat National Agency (BAZNAS) in East Java Province.
\end{abstract}

Keywords: Work Motivation, Employee Commitment, and Employee Perfomance

I.

\section{PENDAHULUAN}

Kemajuan zaman saat ini membuat masyarakat menuntut adanya sebuah lembaga yang baik untuk membantu masyarakat dalam penyelenggaraan program layanan sosial. Saat ini terdapat berbagai macam program kerja sosial yang bergerak pada penyaluran dan pendistribusian zakat salah satunya lembaga Badan Amil Zakat Nasional (BAZNAS). Badan Amil Zakat Nasional(BAZNAS) merupakan lembaga nonstruktural yang terbentuk berdasarkan Undang-Undang No.23 Tahun 2011 tentang Pengelolaan Zakat. Pembentukan BAZNAS pertama kali ditetapkan melalui keputusan Presiden No. 8 tahun 2001 tentang Badan Amil Zakat Nasional, sedangkan Pemerintaah Indonesia mendirikan sebuah Lembaga Pengelolaan Zakat, berdasarkan UndangUndang Nomor 38 tahun 1999 yang mengemukakan bahwa organisasi pengelolaan zakat terdiri dari dua jenis yaitu Badan Amil Zakat dan Lembaga Zakat.

Perintah tentang zakat juga tidak dapat diragukan lagi, hal ini terbukti dalam ayat Al-Qur'an yang menyebutkan dan mengulang hingga 82 kali. Menurut (Qardhawi, 1999) di dalam Al-Qur'an terdapat kurang lebih 27 ayat yangmensejajarkan shalat dengan kewajiban zakat, salah satu ayat tersebut adalah QS At-Taubah ayat 60:

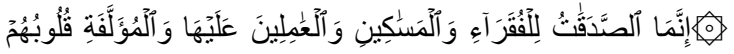

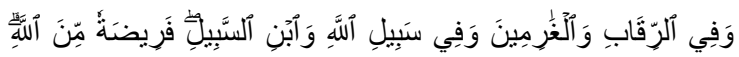

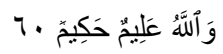

\footnotetext{
${ }^{1}$ Jurnal ini merupakan bagian dari skripsi Amalina Rusydina, NIM: 041311433080 , yang diuji pada tanggal 21 Maret 2019.
} 
'Innamā Aş-Şadaqātu Llilfuqarā-i Wa AlMasākinni Wa Al- 'Āmilina `Alayhā Wa AlMu'vallafati Qulūbuhum Wa FI Ar-Riqābi Wa Al-Ghāriminna Wa FI Sabili Allāhi Wa Aibni As-Sabili, Farīdatan Mina Allāhi Wa, Allāhu `Alimun Ĥakīmun

Artinya: "Sesungguhnya zakat-zakat itu, hanyalah untuk orang-orang fakir, orangorang miskin, pengurus-pengurus zakat, Para mu;allaf yang dibujuk hatinya, untuk (memerdekakam) budak, orang-orang yang berhutang, untuk jalan Allah dan untuk mereka yang sedang dalam perjalanan, sebagai suatu ketetapan yang diwajibkan Allah, dan Allah Maha Mengetahui lagi Maha Bijaksana".

Berdasarkan ayat sebelumnya dapat dijelaskan bahwa Allah SWT memerintahkan hamba-Nya membayar zakat untuk meolong sesama. Artinya yang berhak menerima zakat ialah mereka yang berhutang dan mereka yang tidak mampu memenuhi kebutuhannya dikarenakan kondisi perekonomian yang sangat terbatas.

Motivasi kerja berarti membangkitkan daya gerak, atau menggerakkan seseorang (diri sendiri) untuk berbuat sesuatu dalam rangka mencapai suatu tujuan (Sobur, 2009:268). Islam memandang motivasi ini sebagai sesuatu yang penting, seperti firman Allah SWT dalam Surat Al-Baqarah ayat 148:

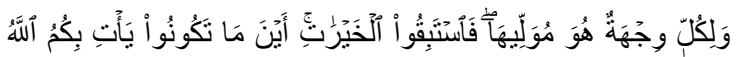

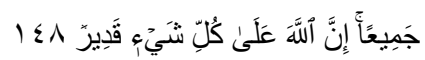
Wa likulliw wijhatun huwa muwallihã fastabiqul-khairãt, aina mã takũnũ ya'ti bi kumullãhu jamĩãa, innallãha 'alã kuli syai' in qadir.

Artinya: Bagi tiap-tiap umat ada kiblatnya (sendiri) yang ia menghadap kepadanya. Maka berlomba-lombalah (dalam membuat) kebaikan. Dimana saja kamu berada pasti Allah akan mengumpulkan kamu sekalian (pada hari kiamat). Sesungguhnya Allah Maha Kuasa atas segala sesuatu. (Depag RI, 2010).

Berdasarkan ayat diatas dapat disimpulkan bahwa motivasi kerja adalah dorongan yang muncul dari dalam diri seseorang ataupun pengaruh dari lingkungan luar yang menyebabkan seseorang tersebut memiliki semangat yang tinggi untuk melakukan kegiatankegiatan guna mencapai suatu tujuan tertentu.

Komitmen karyawan merupakan suatu multi-dimensi yang meliputi loyalitas pekerja, kesediaan mereka untuk mengerahkan usaha lebih atas nama lembaga, kepatuhan terhadap nilai-nilai lembaga, dan keinginan untuk tetap dalam lembaga (Meyer dan Allen, 2013). Allah SWT berfirman dalam surat AlBaqarah ayat 30 :

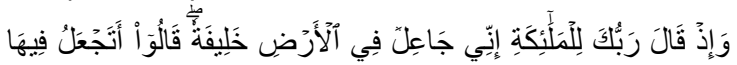

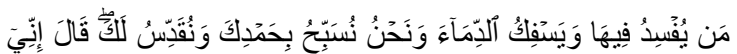

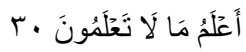

Wa iż qãla rabbuka lil-malã 'ikati innĩ jã ilun fil-arḍi khalifah, qãlũ ataj'alu fîhã may yufsidu fihã wa yasfikud-dimã', wa nahnu nusabbihu bi hamdika wa nuqaddisu lak, qãlã inni a "lamu mã lã ta lamũn. 
Artinya: Ingatlah ketika Tuhanmu berfirman kepada para Malaikat: "Sesungguhnya AkU hendak menjadikan seorang khalifah di muka bumi". Mereka berkata, "mengapa engkau hendak menjadikan (khalifah) di bumi itu orang yang akan membuat kerusakan padanya dan menumpahkan darah, padahal kami senantiasa bertasbih dengan memuji Engkau dan mensucikan Engkau?" Tuhan berfirman: "Sesungguhnya Aku mengetahui apa yang tidak kamu ketahui".

Berdasarkan ayat sebelumnya Allah SWT menjelaskan bahwa seseorang yang dijadikan sebagai khalifah senantiasa akan membuat kerusakan dan menumpahkan darah.

Kinerja karyawan pada dasarnya adalah hasil karya karyawan selama periode tertentu dibandingkan dengan berbagai kemungkinan. Menurut Handoko (2000:135-137) menyatakan bahwa penilaian prestasi kinerja merupakan proses melalui lembaga yang mengevaluasi atau menilai prestasi kinerja karyawan.Manusia mempunyai tujuan hidup, yakni berjuang di jalan kebenaran dan melawan kebatilan. Misi-misi kebenaran adalah misi kebaikan, kerja sama produktif, dan kasih sayang antar manusia. Allah SWT berfirman dalam Surat Al-Kahfi ayat 7 yang berbunyi:

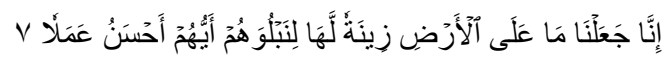
Innã ja aalnã mã ‘alal-arḍi zĩnatal lahã linabluwahum ayuuhum ahsanu 'amalã.
Artinya: Sesungguhnya kami telah menjadikan apa yang di bumi sebagai perhiasan baginya agar kami menguji mereka siapakah di antara mereka yang terbaik perbuatannya.

Rangkaian ayat di atas menjelaskan bahwa Allah SWT akan memberi balasan setiap amal perbuatan manusia bahkan lebih dari apa yang mereka kerjakan. Sehubungan dengan penjelasan di atas, BAZNAS Provinsi Jawa Timur merupakan sebuah lembaga yang bergerak dibidang kemanusiaan. BAZNAS Provinsi Jawa Timur merupakan lembaga yang bertugas untuk membantu masyarakat yang akan menunaikan zakat, infaq, dan shadaqah, wakaf, hibah, dana kemanusiaan lainnya untuk disalurkan kembali kepada yang berhak menerimanya sesuai dengan ketentuan syariat. Penelitian ini akan difokuskan pada karyawan BAZNAS Provinsi Jawa Timur yang sangat erat kaitannya dengan penerimaan dana zakat serta program pemberdayaan ekonomi yang mengandalkan karyawannya. Dengan mengambil populasi karyawan BAZNAS Provinsi Jawa Timur yang berkantor pusat di Jl. Raya Dukuh Kupang No 122-124, Kota Surabaya, dengan fokus penelitian kepada karyawan BAZNAS Provinsi Jawa Timur yang menangani program pemberdayaan ekonomi di lapangan maupun dikantor. Berdasarkan uraian yang telah dijelaskan, maka rumusan masalah dalam penelitian ini adalah: 
1. Apakah terdapat pengaruh dari motivasi kerja terhadap komitmen karyawan BAZNASProvinsi Jawa Timur?

2. Apakah terdapat pengaruh dari komitmen karyawanterhadap kinerja karyawan BAZNASProvinsi Jawa Timur?

3. Apakah terdapat pengaruhdari motivasi kerja terhadap kinerja karyawan BAZNASProvinsi Jawa Timur?

\section{LANDASAN TEORI}

\section{Motivasi Kerja}

Soemanto (1998) mengemukakan bahwa motivasi kerja adalah kondisi internal yang mengarah pada perilaku seseorang untuk mencapai suatu tujuan. Dalam konteks pekerjaan, motivasi adalah dorongan dalam diri individu untuk melakukan pekerjaan baik terhadap pekerjaan yang direncanakan maupun pekerjaan yang sedang dilakukan dalam memenuhi kebutuhan atau tujuan yang ingin dicapai.

\section{Tujuan Motivasi Kerja}

Menurut Hasibuan (2003) tujuan motivasi adalah sebagai berikut:

1. Mendorong moral dan kepuasan kerja karyawan.

2. Meningkatkan produktivitas kerja karyawan.

3. Mempertahankan

kestabilan karyawan.

4. Memingkatkan kedisiplinan dan menurunkan tingkat absensi karyawan.

5. Mengefektifkan pengadaan karyawan.

6. Menciptakan suasana dan hubungan kerja yang baik.
7. Meningkatkan loyalitas, kreatifitas dan partisipasi karyawan.

8. Meningkatkan tingkat kesejahteran karyawan.

9. Mempertinggi rasa tanggung jawab karyawan terhadap tugas-tugas.

10. Meningkat efisiensi penggunaan alatalat dan bahan-bahan baku.

\section{Motivasi Kerja Dalam Perspektif Islam}

Dalam bukunya yang berjudul Bekerja dengan Hati Nurani, (Saleh, 2009:65) mengatakan bahwa selama ini banyak orang bekerja untuk mengajar materi belaka demi kepentingan duniawi, mereka tak sedikitpun memperdulikan kepentingan akhirat kelak. Dalam AlQur'an memberikan penekanan utama terhadap pekerjaan dan menerangkan dengan jelas bahwa manusia diciptakan di bumi untuk bekerja keras mencari penghidupan masing-masing. Sebagaimana firman Allah SWT dalam surat Al-Jumu'ah ayat 10:

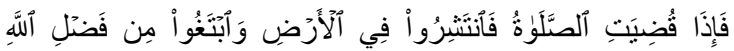

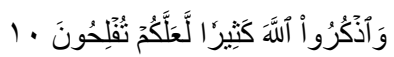

Fa iżã quḍiyatiṣs-ṣalãtu fantasyirū fil-arḍi wabtagū min faḍlillãhi ważkurullāha kașiral la ‘allakum tufliḥūn.

Artinya: "Apabila telah ditunaikan sembahyang, maka bertebaranlah kamu di muka bumi; dan carilah karunia Allah dan ingatlah Allah banyak-banyak supaya kamu beruntung".

Berdasarkan ayat diatas dapat dijelaskan bahwa melihat adanya motivasi yang tersirat berupa keinginan 
untuk memenuhi kebutuhan dengan cara mencari karunia Allah SWT.

\section{Komitmen Karyawan}

Yudha (2014:25) menyebut komitmen karyawan sebagai istilah lain dari komitmen organisasional dan komitmen organisasional merupakan dimensi perilaku yang dapat digunakan untuk menilai kecenderugan karyawan untuk bertahan sebagai anggota perusahaan.

\section{Komitmen Karyawan Dalam Perspektif} Islam

Menurut Yosef (2000) semakin tinggi etika kerja dalam Islam di dalam organisasi maka akan semakin tinggi komitmen yang dimiliki organisasi. Allah SWT berfirman dalam surat Al-Fushshilat ayat 30 :

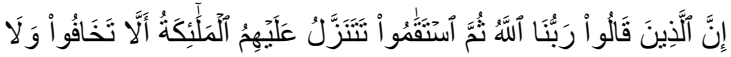

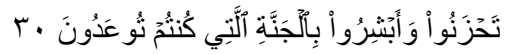
Innallażina qālū rabbunallāhu summastaqāmū tatanazzalu alaihimulmalā ikatu allā takhāfū wa lā tahzanū wa abyirū bil-jannatillatī kuntum tū 'adūn.

Artinya: "Sesungguhnya orang-orang yang menyatakan: "Tuhan kami ialah Allah SWT" kemudian mereka meneguhkan pendirian mereka, maka malaikat akan turun kepada mereka (dengan mengatakan): "janganlah kamu merasa takut dan janganlah kamu merasa sedih, dan bergembiralah kamu dengan (memperoleh) surga yang telah dijanjikan Allah SWT kepadamu"

Berdasarkan ayat diatas dipahami bahwa dengan adanya keteguhan hati yang kuat (keyakinan) dalam diri karyawan maka hal ini akan mendorong karyawan untuk tetap konsisten secara lahir maupun batin.

\section{Kinerja Karyawan}

Menurut Bernandin \& Russel daam Gomes (2003:136) memberi batasan mengenai kinerja sebagai catatan outcome yang dihasilkan dari fungsi suatu pekerjaan tertentu atau kegiatan selama suatu periode waktu tertentu.

\section{Penilaian Kinerja Karyawan}

Mathis dan Jackson (2003:387-393) menjelaskan bahwa penilaian kinerja karyawan dapat dilakukan oleh beberapa penilai yaitu:

1. Penilaian Oleh Atasan Langsung

2. Penilaian Oleh Bawahan

3. Penilaian dari luar

4. Penilaian dari Rekan Kerja

5. Penilaian dari berbgai Sumber

\section{Kinerja Karyawan Dalam Perspektif Islam}

Islam mewajibkan setiap umatnya untuk melaksanakan ibadah, baik ibadah langsung (hablumminaAllah) dan ibadah yang tidak langsung (hablumminannas). Bekerja merupakan bagian ibadah tidak langsung (hablumminannas) sekaligus merupakan kewajiban setiap individu Muslim. Dalam surat At-Taubah ayat 105 Allah SWT berfirman:

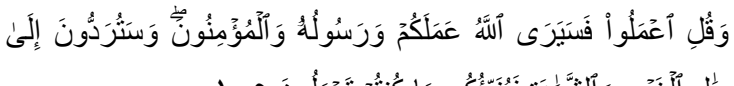

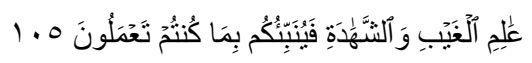
Wa quli'malũ fa sayarallãhu amalakum wa rasũluhũ wal-mu'minũn, wa saturaddũna ilã ãlimil-gaibi wasy- 
syahãdati fa yunnabi'ukum bimã kuntum ta'malũn.

Artinya: "dan Katakanlah: "Bekerjalah kamu, Maka Allah dan Rasul-Nya serta orang-orang mukmin akan melihat pekerjaanmu itu, dan kamu akan dikembalikan kepada (Allah) yang mengetahui akan yang ghaib dan yang nyata, lalu diberitakan-Nya kepada kamu apa yang telah kamu kerjakan." AtTaubah:105(Depag, 1993)

Berdasarkan ayat sebelumnya menunjukkan bahwa bekerja merupakan suatu kewajiban bagi umat Islam sebagai bentuk ibadah kepada Allah SWT.

\section{Definisi BAZNAS Provinsi Jawa Timur}

Pemerintah mendirikan adan Amil Zakat Nasional atau dapat dikenal dengan BAZNAS untuk melakukan kegiatan pengelolaan zakat. BAZNAS juga diberikan tugas dan kewenangan secara nasional dimana dalam menjalankan tugas ini posisi Lembaga Amil Zakat (LAZ) adalah untuk membantu BAZNAS dalam menghimpun dan menyalurkan dana zakat (IZDR, 2012:212).

BAZNAS pusat juga berperan dalam pembentukan kelembagaan BAZNAS Provinsi dan BAZNAS Kabupaten/Kota sesuai dengan UndangUndang Nomor 23 Tahun 2011, yaitu:

Tabel 1.

\section{Ketentuan Pembentukan Kelembagaan}

BAZNAS Provinsi dan Kabupaten/Kota

\begin{tabular}{|c|c|c|}
\hline No. & BAZNAS & BAZNAS \\
& Provinsi & $\begin{array}{c}\text { Kabupaten/ } \\
\text { Kota }\end{array}$ \\
\hline
\end{tabular}

\begin{tabular}{|c|c|c|}
\hline 1. & $\begin{array}{l}\text { Dipimpin oleh } \\
\text { Menteri atas } \\
\text { usulan } \\
\text { Gubernur }\end{array}$ & $\begin{array}{l}\text { Dipimpin Dirjen } \\
\text { atas usulan } \\
\text { Bupati/Walikota }\end{array}$ \\
\hline 2. & $\begin{array}{l}\text { Bila tidak ada } \\
\text { usulan, Menteri } \\
\text { yang ditunjuk } \\
\text { dapat } \\
\text { membentuk } \\
\text { BAZNAS Provinsi } \\
\text { dengan } \\
\text { pertimbangan } \\
\text { BAZNAS }\end{array}$ & $\begin{array}{c}\text { Bila tidak ada } \\
\text { usulan, Dirjen } \\
\text { yang ditunjuk } \\
\text { dapat } \\
\text { membentuk } \\
\text { BAZNAS } \\
\text { Kabupaten/Kota } \\
\text { dengan } \\
\text { pertimbangan } \\
\text { BAZNAS }\end{array}$ \\
\hline 3. & $\begin{array}{l}\text { Melaksanakan } \\
\text { tugas dan } \\
\text { fungsi di } \\
\text { Provinsi }\end{array}$ & $\begin{array}{l}\text { Melaksanakan } \\
\text { fungsi dan tugas } \\
\text { di } \\
\text { Kabupaten/Kota }\end{array}$ \\
\hline 4. & $\begin{array}{c}\text { Dapat } \\
\text { membentuk } \\
\text { UPZ (Unit } \\
\text { Pengumpulan } \\
\text { Zakat) }\end{array}$ & $\begin{array}{c}\text { Dapat } \\
\text { membentuk UPZ } \\
\text { (Unit } \\
\text { Pengumpulan } \\
\text { Zakat) }\end{array}$ \\
\hline
\end{tabular}

Sumber: UU No.23 Tahun 2011 Pasal 5

Sumber pendanaan pada BAZNAS bersumber pada pendanaan dari APBN dan hak amil. Bila dibandingkan dengan LAZ, maka BAZNAS memiliki sumber pembiayaan yang lebih dibandingkan dengan LAZ, namun tugas BAZNAS lebih berat dalam mengkoordinir, membina, dan mengawasi LAZ (Alam, 2015:30).

Fungsi dan Tugas BAZNAS Provinsi Jawa Timur

Hafidhuddin

(2002:126)

menyatakan bahwa melakukan pengelolaan zakat dibutuhkan lembaga 
khusus untuk mengelola zakat yang memiliki kekuatan hukum formal karena memiliki beberapa manfaat yaitu:

a. Menjaga perasaan diri para mustahik zakat apabila berhadapan langsung untuk menerima zakar dari para muzakki.

b. Mencapai efisiensi dan efektivitas serta sasaran yang tepat dalam penggunaan harta zakat menurut skala prioritas yang ada pada suatu tempat.

c. Menunjukkan syiar Islam dalam semangat penyelenggara Pemerintah yang Islami.

\section{Hubungan Antara Motivasi Kerja Terhadap Komitmen Karyawan}

Menurut George dan Jones (dalam Moi, 2017:6) mendefinikan bahwa motivasi kerja sebagai suatu dorongan secara psikologis kepada seseorang yang menentukan arah dari perilaku (direction of behavior) seseorang dalam perusahaanm tingkat usaha (level of effort), dan tingkat kegigihan atau ketahanan di dalam menghadapi suatu halangan atau masalah (level of persistence).

Purnama (2016) dalam penelitiannya tentang motivasi kerja dan komitmen karyawan menyatakan bahwa terdapat pengaruh positif antara variabel motivasi kerja terhadap komitmen karyawan.

\section{Hubungan Antara Komitmen Karyawan Terhadap Kinerja Karyawan}

Komitmen karyawan menunjuk pada pengidentifikasian tujuan karyawan dengan tujuan perusahaan, kemauan mengerahkan segala daya untuk kepentingan perusahaan dan keterikatan untuk tetap menjadi bagian dari perusahaan serta mempertahankan nilainilai dengan munculnya kesamaan niai dari perusahaan tersebut (Porter et.al dalam Darwito, 2008).

Shahab (2010) dalam penelitiannya tentang komitmen dan kinerja karyawan pada perusahaan menyatakan bahwa terdapat pengaruh positif antara variabel komitmen karyawan terhadap kinerja karyawan.

\section{Hubungan Antara Motivasi Kerja Terhadap Kinerja Karyawan}

Motivasi dalam bekerja sangat penting untuk meningkatkan produktivitas perusahaan dan menjaga komitmen karyawannya agar kepentingan dan tujuan perusahaan dapat tercapai. Meningkatkan kinerja karyawan secara otomatis akan meningkatkan kinerja di perusahaannya (Wibowo, 2013:378).

Azizah (2013) dalam penelitiannya tentang pengaruh motivasi kerja dan kinerja karyawan menyatakan bahwa ada pengaruh hubungan yang positif atara motivasi kerja dengan pencapaian kinerja karyawan.

\section{Hipotesis dan Model Analisis}

Hipotesis adalah dugaan sementara atas suatu persoalan yang masih perlu dibuktikan kebenarannya dan harus bersifat logis, jelas dan dapat diuji kebenarannya. Hipotesis dalam penelitian ini adalah: 
$\mathrm{H}_{1}=$ Motivasi kerja berpengaruh terhadap komitmen karyawan BAZNASProvinsi Jawa Timur

$\mathrm{H}_{2}=$ Komitmen karyawan berpengaruh terhadap kinerja karyawanBAZNAS Provinsi Jawa Timur

$\mathrm{H}_{3}=$ Motivasi kerja berpengaruh terhadap kinerja karyawanBAZNAS Provinsi Jawa Timur

III. METODOLOGI PENELITIAN

Menurut Sugiyono (2003:14), penelitian kuantitatif adalah penelitian dengan maksud memperoleh data yang berbentuk angka atau data kualitatif yang diangkakan.

Ditinjau dari tujuannya, penelitian ini pendekatan penelitian yang digunakan dalam penelitian ini adalah kuantitatif eksplanatif. Menurut Priyono (2008:38) Penelitiain kuantitatif eksplanatif adalah penelitian yang menjelaskan hubungan antar variabel. Penelitian ini dilakukan untuk menemukan penjelasan tentang mengapa suatu kejadian atau gejala yang terjadi.

\section{Identifikasi Variabel}

Menurut Sugiyono (1999), variabel penelitian adalah sesuatu hal yang berbentuk apa saja yang ditetapkan oleh peneliti untuk dipelajari sehingga diperoleh informasi tentang hal tersebut kemudian ditarik kesimpulannya. Dalam penelitian ini menggunakan tiga variabel yaitu variabel eksogen, variabel endogen intervening, variabel endogen.

\section{Definisi Operasional}

Berikut dijabarkan definisi operasinal variabel sebagai pijakan atas variabel-variabel yang digunakan untuk kemudian diuji dalam bab pemabahasan selanjutnya:

1. Variabel Eksogen (Motivasi Kerja)

Soemanto (1998) mengemukakan bahwa motivasi kerja adalah kondisi internal yang mengarah pada perilaku seseorang untuk mencapai suatu tujuan. Dengan demikian, definisi operasional motivasi kerja adalah motivasi karyawan BAZNAS Provinsi Jawa Timur yang bersedia bekerja dengan sepenuh hati untuk mencapai tujuan perusahaan.

2. Variabel Endogen Intervening (Komitmen Karyawan)

Safaria (2004:198) mendefinisikan komitmen sebagai keinginan yang kuat untuk tetap menjadi anggota perusahaan dan percaya sehingga mengakibatkan motivasi dan upaya yang tinggi untuk memberikan hal terbaik, kesuksesan, dan kemajuan bagi perusahaan. Dengan demikian, definisi operasional komitmen karyawan adalah keyakinan hati karyawanBAZNAS Provinsi Jawa Timur Provinsi Jawa Timur untuk bersedia bekerja sepenuh hati untuk mencapai tujuan perusahaan dengan menaati aturan kerja yang berlandaskan Islam secara konsisten.

3. Variabel Endogen (Kinerja Karyawan) 
Mangkunegara (2001:67) mengatakan bahwa kinerja merupakan hasil kerja yang diukur secara kualitas dan kuantitas pencapaian seorang karyawan dalam melaksanakan tugasnya sesuai dengan tanggung jawab yang diberikan kepadanya. Dengan demikian definisi operasional untuk variabel kinerja karyawan adalah hasil kerja karyawan BAZNAS Provinsi Jawa Timur sesuai dengan tanggung jawab masing-masing dalam upaya untuk mencapai tujuan lembaga yang diukur secara kuantitas.

\section{Jenis dan Sumber Data}

Sumber data yang digunkaan dalam penelitian ini adalah data primer dan data sekunder, yaitu diperoleh dari hasil jawaban responden atas kuisioner serta wawancara dengan karyawan BAZNAS. Sedangkan sumber data sekunder diperoleh dari profil BAZNAS, jurnal, foto dokumentasi lapangan, dan website.

\section{Polulasi dan Sampel Penelitian}

Indriantoro dan Supomo (2002:115-

116) populasi merupakan sekelompok orang, kejadian atau segala sesuatu yang mempunyai karakteristik tertentu. Populasi dalam penelitian ini yaitu seluruh karyawan BAZNAS Provinsi Jawa Timur.

Menurut Anshori dan Iswati (2009:94) jumlah anggota sampel yang paling tepat digunakan dalam penelitian bergantung pada tingkat kepercayaan atau tingkat kesalahan yang dikehendaki. Berdasarkan penjelasan tersebut, jumlah sampel yang digunakan adalah 40 responden. Sampel yang digunakan adalah karyawan BAZNAS Provinsi Jawa Timur yang bekerja minimal selama 1 tahun karena dapat memenuhi target kinerja.

\section{Teknik Analisis Data}

Teknik analisis yang digunakan dalam penelitian ini adalah analisis jalur (path analysis). Analisis jalur merupakan model perluasan regresi yang digunakan untuk menguji keselarasan matriks korelasi dengan dua atau lebih model hubungan sebab akibat yang dibandingkan oleh peneliti (Garson, 2003 dalam Pardede dan Manurung, 2014:17).

Terdapat alasan-alasan mengenai penggunaan path analysis yang dijelaskan oleh Bungin (2005:225), yaitu sebagai berikut:

1. Apabila data yang akan dianallisis adalah skala interval atau rasio dan data ordinal.

2. Plot-plot dari distribusi nilai variabelvariabel membentuk garis lurus

3. Ada kesamaan varian yaitu distribusi nilai dari variabel-variabel disepanjang garis lurus mempunyai jarak yang kirakira sama.

4. Persebaran nilai dari variabel apabila digambarkan maka membentuk grafik normal.

\section{Pengujian Hipotesis}

Penelitian ini menggunakan menggunakan srtuktural untuk variabel endogen intervening (Z) adalah (Solimun, 2002:97): 


$$
Z=\gamma X+e
$$

Keterangan:

Z : Komitmen Karyawan BAZNAS Provinsi Jaw Timur

Y : Koefisien path dari variabel eksogen ke variabel endogen

X : : Motivasi Kerja

e : Standard Error

Penelitian ini juga menggunakan persamaan struktural untuk variabel endogen $(Y)$, yaitu:

$$
Y=Y=\beta Z+Y X+e
$$

$Y \quad$ : Kinerja Karyawan BAZNAS Provinsi Jawa Timur

B : Koefisien dari path variabel endogen ke variabel eksogen

Z : Komitmen Karyawan BAZNAS

Provinsi Jawa Timur

Y : Koefisien path dari variabel eksogen ke variabel endogen

X : Motivasi Kerja

E : Strandard error

IV. PEMBAHASAN

\section{Pengaruh Motiivasi Kerja Terhadap Komitmen Karyawan}

Hasil penelitian menunjukkan bahwa variabel motivasi kerja berpengaruh signifikan terhadap komitmen karyawan dengan nilai $C R$ hitung 11,127. Tingkat signifikan diperoleh dari nilai 0,000, nilai ini lebih kecil dari 0,05. Maka hal ini menunjukkan bahwa hipotesis yang pertama dapat diterima.

Hal ini yang mendukung indikator variabel motivasi kerja yang pertama, yaitu terdorong karena tidak merasa terbebani dengan tanggung jawab yang diberikan oleh pimpinan. Dimana kesungguhan tersebut karyawan dapat menyelesaikan tugas dengan baik tanpa merasa terbebani oleh tugasnya. Jawaban responden menunjukkan bahwa karyawan BAZNAS memiliki rasa tanggung jawab yang tinggi dalam menyelesaikan tugasnya, sehingga komitmen karyawan untuk melakukan pekerjaan pun juga tinggi.

Hasil penelitian ini sejalan dengan penelitian yang dilakukan oleh Purnama (2016) yang menunjukkan hasil bahwa motivasi kerja yang tinggi akan secara signifikan meningkatkan komitmen karyawan. Pemberian dorongan motivasi kerja merupakan salah satu cara menumbuhkan komitmen karyawan. Dalam hal ini semakin tinggi motivasi kerja seorang karyawan maka karyawan itu akan memiliki komitmen yang tinggi.

Dengan demikian dapat disimpulkan bahwa motivasi kerja yang tinggi akan meningkatkan komitmen karyawan, sebaliknya jika motivasi kerja yang diterapkan di Badan Amil Zakat Nasional Provinsi Jawa Timur kurang baik maka komitmen karyawan akan menurun.

\section{Pengaruh Komitmen Karyawan Terhadap} Kinerja Karyawan

Hasil penelitian menunjukkan bahwa komimen karyawan BAZNAS Provinsi Jawa Timur berpengaruh signifikan terhadap kinerja karyawan dengan nilai CR hitung 5,709. Tingkat signifikan diperoleh dari nilai 0,000 , nilai ini lebih kecil 
dari 0,005. Maka menunjukkan bahwa hipotesis kedua ini diterima.

Hal ini yang mendukung indikator variabel komitmen karyawan yang keenam, yaitu karyawan BAZNAS lebih mengutamakan kepentingan tijaroh/bersama daripada kepentingan pribadi. Dimana kesungguhan tersebut muncul ketika seorang karyawan telah berkomitmen terhadap pekerjaannya. Jawaban responden menunjukkan bahwa karyawan memiliki kesungguhan dalam bekerja dan berusaha yang terbaik secara istiqomah serta lebih mengutamakan kepentingan perusahaan sehingga kinerja karyawan akan meningkat.

Hasil penelitian ini sejalan dengan penelitian yang dilakukan oleh Shahab (2010) yang menunjukkan hasil bahwa terdapat pengaruh positif dari variabel komitmen karyawan terhadap kinerja karyawan, dikarenakan semakin tinggi tingkat komitmen karyawannya maka akan meningkatkan tanggung jawab karyawan terhadap perusahaan, sehingga kinerjanya semakin tinggi pula.

Dengan demikian dapat disimpulkan bahwa komitmen karyawan yang baik akan meningkatkan kinerja karyawan, sebaliknya jika komitmen karyawan di Badan Amil Zakat Nasional (BAZNAS) Provinsi Jawa Timur kurang baik, maka kinerja karyawan akan menurun.

Pengaruh Motivasi Kerja Terhadap Kinerja Karyawan
Hasil penelitian menunjukkan bahwa motivasi kerja berpengaruh signifikan terhadap kinerja karyawan BAZNAS Provinsi Jawa Timur dengan nilai CR hitung 2,561. Tingkat signifikan diperoleh dari nilai 0,000, nilai ini lebih kecil dari 0,05. Maka hal ini dapat menunjukkan bahwa hipotesis yang ketiga dapat diterima.

Hal ini yang mendukung indikator variabel kinerja karyawan yang kedua belas yaitu sebagai karyawan BAZNAS mampu menunjukkan prestasi sebagai perwujudan hasil kerja keras dan rasa selalu ingin maju. Dimana kesungguhan tersebut karyawan dapat menunjukkan hasil kinerjanya dengan prestasi yang diperoleh.Jawaban responden menunjukkan bahwa karyawan memiliki rasa selalu ingin maju agar hasil kinerjanya pun juga semakin meningkat.

Hasil penelitian ini sejalan dengan penelitian yang dilakukan oleh Azizah (2013) yang menunjukkan hasil bahwa ada pengaruh hubungan yang positif antara motivasi kerja dengan pencapaian kinerja karyawan.

Dengan demikian dapat disimpulkan bahwa motivasi kerja sangat mempengaruhi kinerja karyawan, karena jika karyawan tidak benar-benar memiliki motivasi kerja yang tinggi maka hasil kinerjanya akan menurun. Berdasarkan penjelasan pembahasan dari hasil penelitian dapat dijelaskan bahwa pengaruh yang lebih besar yaitu dari variabel motivasi kerja terhadap 
komitmen karyawan dengan nilai sebesar 0,872 karena untuk memiliki komitmen yang tinggi juga harus memiliki motivasi kerja yang tinggi.

V. KESIMPULAN

Berdasarkan hasil pengolahan data serta pembahasan yang telah dilakukan, maka dapat disimpulkan sebagai berikut:

1. Motivasi kerja berpengaruh signifikan terhadap komitmen karyawan Badan Amil Zakat Nasional (BAZNAS) Provinsi Jawa Timur.

2. Komitmen karyawan berpengaruh signifikan terhadap kinerja karyawan Badan Amil Zakat Nasional (BAZNAS) Provinsi Jawa Timur..

3. Motivasi kerja berpengaruh signifikan terhadap kinerja karyawan Badan Amil Zakat Nasional (BAZNAS) Provinsi Jawa Timur.

\section{DAFTAR PUSTAKA}

Akbar, N. 2009. Analisis Efisiensi Organisasi Pengelola Zakat Nasional Dengan Pendekatan Data Envelopment Analysis. Jurnal Islamic Finance and Business Vol. 4 No. 2. Bogor. Tazkia

Anna, Suzanthi. 2014. The Role of Work Motivation in Mediatet the Influence of Transformasional Leadership on the Perfomance (Study on PT. Terminal Peti Kemas Surabaya.

Amin, Ayoeb. 2010. Pengaruh Komitmen Kerja Islami Terhadap Motivasi Kerja dan Status Pendapatan Serta Kesejahteraan Keluarga Muslim di
Kabupaten Pkelongan, Provinsi Jawa Tengah. Disertasi Tidak Diterbitkan. Fakultas Ekonomi dan Bisnis Universitas Airlangga.

Azizah. 2013. Pengaruh Motivasi Spiritual Islam Terhadap Kinerja Islam Karyawan BRI Syariah $\mathrm{KCl}$ Surabaya Gubeng. Fakultas Ekonomi dan Bisnis Universitas Airlangga.

Anshori, Muslich dan Sri Iswati. 2009. Metode Penelitian Kuantitatif. Surabaya: Airlangga: Pusat Penerbitan dan Percetakan UNAIR (AUP).

Beik, Irfan Syauqi. 2008. Pro Ekonomi Syariah Pro Rakyat. Jakarta: Republika.

Budiastiti, Alfitta. 2015. Pengaruh Kepemimpinan Islam Terhadap Komitmen Kerja dan Kinerja Kerja Karyawan Baitul Maal Hidayatullah (BMH) Surabaya. Skripsi tidak diterbitkan. Surabaya: Universitas Airlangga.

Bungin, Muhammad Burhan. 2005. Metode Penelitian Kuantitatif. Edisi Pertama. Jakarta: Kencana.

Chrisnanda. 2017. Pengaruh Motivasi Kerja Terhadap Kinerja Karyawan di PT. MAS SUMBIRI

Darwito, 2008. Analisis Pengaruh Gaya Kepemimpinan Terhadap Kepuasan Kerja Dan Komitmen Organisasi Untuk Meningkatkan Kinerja Karywan /Studi Kasus Pada RSUD Semarang). Tesis Tidak 
Diterbitkan. Universitas Diponegoro Semarang.

Departemen Agama RI. 2002. Mushaf AlQuran Terjemah. Jakarta: Al-Huda. Fadhlur R, Ridhan. 2013. Pengaruh Etos Kerja Islam Terhadap Kinerja Islam Karyawan Dengan Variabel Moderator Motivasi Kerja Pada Bank Muamalat di Surabaya. Skripsi tidak diterbitkan. Fakultas Ekonomi dan Bisnis Universitas Airlangga.

Ferdinand, Augusty. 2002. Structural Equation Modelling (SEM) dalam Penelitian Manajemen. Semarang: Badan Penerbit Universitas Diponegoro.

Frances K. Stages, Carter, dan Nora. 2004. Path Analysis: An Introduction and Analysis of a Decode of Research. The Journal of Educational Research (98-1. 5-12).

Hafidhuddin, Didin 2002. Zakat Dalam Perekonomian Modern. Jakarta: Gema Insani Pers.

Hair, Black and Babin Anderson. 2006. Multivariate Data Analysis. Sixth Edition. New Jersey: Pearson Prentice Hall.

Hasibuan, S.P. Malayu, 1995. Manajemen Sumber Daya Manusia, Edisi Kedelapan, Jakarta: PT. Gunung Agung.

Kirana, Kusuma Chandra. 2014. Pengaruh Implementasi Kepemimpinan Muslimah Terhadap Komitmen dan Kinerja Serta Kesejahteraan Karyawan Pada Sub Sektor Industri
Bank Tulis di Pulau Jawa. Disertasi Tidak Diterbitkan. Universitas Airlangga Surabaya.

Kuncoro, Mudrajad. 2003. Metode Riset Untuk Bisnis dan Ekonomi. Jakarta: Erlangga.

Kuncoro, Ahmad dkk. 2008. Analisis Jalur (Path Analysis). Edisi Kedua. Bandung: Alfabeta.

Kusumawardani, Dyah Ayu. 2011. Studi Mengenai Keputusan Pembelian Jasa Wedding Organizer And Abu Jesh Zeel Arsh, dan Taufik Hamim, dan Hidayatullah Hamim. 2011. Ensiklopedia Nabi Muhammad SAW Sebagai Pemimpin. PT Lentera Abadi: Jakarta.

Malhotra, N.K. 2004. Marketing Research: An Apllied Orientation. Edisi Keempat. New Jersey: Pearson Education Inc.

Mangkunegara, Anwar Prabu. 2000. Manajemen Sumber Daya Manusia Perusahaan. Bandung: PT. Remaja Rosdakarya.

Mathis, R.L., dan J.H. Jackson. 2001. Manajemen Sumber Daya Manusia. Terjemahan, Edisi Kesepuluh. Salemba Empat: Jakarta.

R.L., dan J.H. Jackson. 2003. Manajemen Sumber Daya Manusia. Terjemahan, Edisi Kesepuluh. Salemba Empat: Jakarta.

Miner, John. 1998. Manajemen Kepemimpinan Muhammad SAW: 
$\begin{array}{lrr}\text { Mencontoh } & \text { Teladan } \\ \text { Kepemimpinan } & \text { Rasul Untuk }\end{array}$ Kesempurnaan Manajemen Modern. Terjemahan oleh M. Rudi Atmoko. 2011. Bandung: PT. Misan Pustaka.

Pamungkas, Astria Dyah Ayu. 2014. Pengaruh Gaya Kepemimpinan Otoraksi Terhadap Kinerja Karyawan Melalui Mediasi Kesempurnnaan Manajemen Modern. Terjemahan oleh M. Rudi Atmoko. 2011. Bandung: PT. Misan Pustaka.

Putri. 2014. Hubungan Motivasi Kerja Dengan Komitmen Kerja Karyawan di Balai Pendidikan dan Pelatihan Sosial.

Ratnasari, Ririn Tri. 2014. Kepemimpinan Islam dan Pemasaran Internal Terhadap Kinerja Serta Kesejahteraan Karyawan Bank Islam di Jawa Timur. Disertasi tidak diterbitkan. Surabaya: Universitas Airlangga.

Safaria, Triantoro. 2004. Kepemimpinan. Yogyakarta: Graha IImu.

Sanusi, Anwar. 2011. Metode Penelitian Bisnis. Jakarta: Salemba Empat.

Shihab, M.Qurasih. 2009. Tafsir Al-Misbah. Jakarta: Lentera Hati.

Sugiyono. 2011. Metode Penelitian Kuantitatif, Kualitatif, dan R\&D. Bandung: Alfabeta.

Solimun, 2002. Multivariate Analysis Structural Equation Modelling (SEM)
Lisrel dan Amus. Fakultas MIPA. Universitas Brawijaya Malang.

Tantri, Yanuar. 2018. The Influence of Compensation and Motivation Towards The Perfomance Mediated By Organizational Commitment: Study on HR \& GA Employees In PT. GAJAH TUNGGAL Tbk, Indonesia.

Taryono Asa, 2012, Potensi Zakat Nasional Mencapai Rp 217 triliun, (http://www.harianterbit.com Diakses 7 Mei 2018).

Tasmara, Toto. 2002. Membudayakan Etos Kerja Islami. Jakarta; Gema Insani. Toto 2006. Spiritual Centered Leadership (Kepemimpinan Berbasis Spiritual). Jakarta: Gema Insani.

Rivai, Veithzal dan Basri. 2005. Perfomance Appraisal: Sistem yang Tepat Untuk Menilai Kinerja Karyawan dan Meningkatkan Daya Saing Perusahaan. Jakarta: PT. Raja Grafindo Persada.

------, 2009. Islamic Human Capital. Jakarta: Rajawali Pers.

-------, dan Arviyan Arifin. 2009. Islamic Leadership: Membangun Superleadership Melalvi Kecerdasan Spiritual. Jakarta: PT. Bumi Aksara.

Undang-Undang Republik Indonesia No. 23 Tahun 2011 Tentang Pengelolaan Zakat. 
Republik Indonesia No. 38

Tahun 1999 Tentang Pengelolaan

Zakat.

Widhiarso, Wahyu. 2005. Melibatkan Rater Dalam Pengembangan Alat Ukur. Artikel diakses 30 Mei 2018. Fakultas

Psikologi Universitas Gajah Mada.

www.alquran-indonesia.com

www.baznasjatim.or.id 